\title{
Psychometric Properties of the 20-Item Toronto Alexithymia Scale in a Group of Italian Younger Adolescents
}

\author{
Giuseppe Craparo ${ }^{1}$, Palmira Faraci ${ }^{1}$, and Alessio Gori ${ }^{2}$ \\ ${ }^{1}$ Faculty of Human and Social Sciences, Kore University of Enna, Enna, Italy \\ ${ }^{2}$ Department of Psychology, University of Florence, Florence, Italy
}

Objective Alexithymia is a personality construct that inhibits and interferes with normal affect regulating abilities. The purpose of our study was to assess psychometric properties of TAS-20 in younger adolescents.

Methods Data were collected from 508 younger adolescents ( $48.8 \%$ male and $51.2 \%$ female) with a mean age of 12.56 years (DS=0.50, range: $12-13$ years). We administered the following scales: 20 -Item-Toronto Alexithymia Scale.

Results The confirmatory factor analysis performed on the second random subsample showed reasonable goodness-of-fit for the oblique bi-factorial model: $[\mathrm{chi}]^{2}(32, \mathrm{n}=254)=54.22 ; \mathrm{p}=0.008 ; \chi^{2} / \mathrm{df}=1.69 ; \mathrm{NNFI}=0.92 ; \mathrm{CFI}=0.95 ; \mathrm{SRMR}=0.05 ; \mathrm{RMSEA}=0.05 ; 90 \%$ confidence interval $=0.027-0.078$.

Conclusion Based on the outcomes of our research we support the idea of evaluating adolescents for alexithymia.

Psychiatry Investig 2015;12(4):500-507

Key Words Alexithymia, Factorial model, Adolescence, TAS-20, Validation.

\section{INTRODUCTION}

Alexithymia is a personality construct that inhibits and interferes with normal affect regulating abilities. ${ }^{1,2}$ The term alexithymia (derived from the Greek a=lack, lexis=word and thymos=mood) was introduced by Sifneos ${ }^{3}$ to indicate a cognitive-affective disturbance that affects the way individuals regulate their emotions. ${ }^{2,4}$ This personality construct has been conceptualized to comprise multiple facets including: 1) difficulty identifying and distinguishing emotions from bodily sensations; 2) difficulty describing and verbalizing emotions; 3) poverty of fantasy life; 4) externally oriented thinking style; and 5) poor empathizing. ${ }^{5}$

Alexithymia should be considered as a risk factor for those medical, psychiatric, or behavioral problems that are influenced by disordered affect regulation; ${ }^{2}$ in fact, it is hypothe-

Received: January 20, 2015 Revised: March 3, 2015

Accepted: March 3, 2015 Available online: September 30, 2015

$\triangle$ Correspondence: Giuseppe Craparo, PhD

Faculty of Human and Social Sciences, Kore University of Enna, Cittadella Universitaria 1, Enna 94100, Italy

Tel: +39 0935536536, Fax: +390935536943

E-mail: giuseppe.craparo@unikore.it

(a) This is an Open Access article distributed under the terms of the Creative Commons Attribution Non-Commercial License (http://creativecommons.org/licenses/by$\mathrm{nc} / 3.0$ ) which permits unrestricted non-commercial use, distribution, and reproduction in any medium, provided the original work is properly cited. sized that this personality constructs is one of several factors that contribute to various physical and mental health problems including undifferentiated negative moods such as depression and anxiety, compulsive or addictive behaviors, heightened or prolonged, physiological arousal, physical symptoms, and potentially somatic disease. ${ }^{6,7}$

A considerable literature has amassed documenting strong associations of alexithymia with a range of mental disorders in community samples, but there's still a need for data concerning the epidemiology of alexithymia among teenagers in the general population. In fact, it is therefore important to study the extent and impact of alexithymia in youth, particularly in adolescence. $^{8-11}$

Although research with preadult populations is still relatively limited, growing evidence suggests that alexithymia may have the same consequences for well-being and health in adolescence as in adulthood. ${ }^{10}$ Particularly some researches have shown an association between alexithymia and behavioral problems in adolescents. Much of the existing adolescent alexithymia research, that has been conducted with the 20-Item Toronto Alexithymia Scale, ${ }^{12,13}$ showed associations between this construct and dissociative tendencies, ${ }^{14}$ Eating Behavior Disorders ${ }_{1}^{15}$ Post-Traumatic Stress Disorder, ${ }^{16}$ Emotional Intelligence, ${ }^{17}$ and Abuse. ${ }^{18}$ 
Although the TAS-20 has been and is still being used with adolescent respondents, the psychometric properties of this measure have not been systematically evaluated in preadult populations in the Italian context. Rieffe et al. ${ }^{8}$ developed a Dutch-language self-report measure of alexithymia for children and adolescent, by rewording the items from the original TAS-20 scale to make them adequate to a preadolescent population, because in its present form the TAS-20 may not be suitable for use with adolescents. ${ }^{10}$

Taking into consideration this interesting and innovative work and also the conclusion reached in the work of Parker et al..$^{10}$ demonstrating that the use of the TAS-20 with teenage respondents is not recommended without appropriate adaptation, this study aims to investigate the psychometric properties of an adapted Italian version of the TAS-20 in an adolescent population.

\section{METHODS}

\section{Participants and procedure}

Data were collected from 508 younger adolescents (48.8\% male and $51.2 \%$ female) with a mean age of 12.56 years (DS= 0.50 , range: $12-13$ years).

Exploratory factor analysis was conducted on a first random subsample of 254 participants, $48 \%$ men and 52\% women, with a mean age of 12.54 years ( $\mathrm{SD}=0.50$, range: $12-13$ years).

Confirmatory factor analysis was conducted on a second randomly selected 254 participant subsample, $49.6 \%$ men and $50.4 \%$ women, with a mean age of 12.56 years $(\mathrm{SD}=0.50$, range: $12-13$ years). These two subsamples of participants were compared with regard to demographic characteristics. Chi square test and Student's independent samples t-test were used to evaluate differences in the distribution of gender and age between the two groups. The two sets of data are comparable in terms of both gender $\left(\chi^{2}=0.283, p=0.594\right)$ and age $(\mathrm{t}=-0.53, \mathrm{df}=506, \mathrm{p}=0.593)$.

The instrument was administered to students in southern Italy. All participants provided written consent.

\section{Instrument}

TAS-2012, ${ }^{13}$ is a self-report measure of alexithymia. It consists of three subscales: Difficulty identifying feeling (7 items; e.g., "I am often confused about what emotion I am feeling"); Difficulty describing feelings (5 items; e.g., "It is difficult for me to find the right words for my feelings"); and Externally oriented-thinking (8 items; e.g., "I prefer talking to people about their daily activities rather than their feelings"). Cut-off scores are as follow: $\leq 50=$ no alexithymia, $51-60=$ borderline alexithymia, and $\geq 61=$ alexithymia. The Italian reliability, construct, and criterion validity of scores on the TAS-20 have been well established in various samples of adults. ${ }^{19,20}$

\section{Data analyses}

A preliminary inspection of the item distribution was conducted to assess the extent to which TAS-20 items could be factor analyzed using normal-theory estimation procedures. The normality of data was checked through KolmogorovSmirnov and Shapiro-Wilk tests.

Psychometric evaluation of the TAS-20 was initiated with examination of the distributional properties and response frequencies.

Exploratory factor analysis was performed to determine the underlying dimensions of the questionnaire, using various criteria of item selection according to the number of selected factors and item factor loadings. Prior to EFA, data were inspected to ensure items were significantly correlated, using Bartlett's Test of Sphericity, and shared sufficient variance, using Kaiser-Meyer-Olkin (KMO) Measure of Sampling Adequacy to evaluate whether items share sufficient variance to justify factor extraction.

Sampling adequacy values that are less than 0.50 are considered unacceptable, values that are between 0.50 and 0.60 are considered marginally acceptable, and values greater than 0.80 and 0.90 are considered excellent. ${ }^{21}$ Principal axis factoring was selected as the method of factor extraction. An oblique rotation method (promax criterion) was selected to obtain a simple structure since there was no theoretical assumption suggesting that the factors were independent from each other.

The number of factors to extract was determined performing random data parallel analyses. ${ }^{22}$ The eigenvalues derived from the actual data were compared to the eigenvalues derived from the random data. Factors were retained as long as the ith eigenvalue from the actual data was greater than the ith eigenvalue from the random data. ${ }^{23}$ Both Kaiser ${ }^{24}$ criterion and the scree test ${ }^{25}$ were checked for agreement. Salience was detected applying the following three criteria: 1 ) a factor loading of at least 0.3 on the primary factor, ensuring a high degree of association between the item and the factor, 2) when an item was loading simultaneously on two factors, a difference of 0.3 between loading on the primary factor and loading on other factors, ensuring that each item could be considered salient to one factor, 3) a minimum of three items for each factor, so ensuring meaningful interpretation of stable factors. ${ }^{26}$

To investigate to what extent the factor scores were intercorrelated the standard Pearson product moment correlation coefficient was used.

The reliability of the scale, in terms of internal consistency, was computed by coefficient alpha. Corrected item-scale correlations were examined for each of the revealed subscales. For item selection it was decided that adjusted item-total correla- 
Table 1. Item analysis and response frequency

\begin{tabular}{|c|c|c|c|c|c|c|c|c|c|c|c|c|}
\hline Item & M & DS & $\mathrm{S}$ & $\mathrm{K}$ & $\mathrm{K}-\mathrm{S}$ & S-W & $\%$ Sd & $\% \mathrm{D}$ & $\% \mathrm{~Pa}$ & $\% \mathrm{~A}$ & $\% \mathrm{Sa}$ & $\%$ Missing \\
\hline \multicolumn{13}{|c|}{ Subsample $1(\mathrm{~N}=254)$} \\
\hline Item 1 & 2.71 & 1.34 & 0.36 & -1.11 & $0.24^{* * *}$ & $0.88^{* * *}$ & 20.5 & 32.7 & 15 & 18.1 & 13.4 & 0.4 \\
\hline Item 2 & 3.04 & 1.40 & -0.12 & -1.30 & $0.20^{* * *}$ & $0.89^{* * *}$ & 19.7 & 18.5 & 16.9 & 27.2 & 17.3 & 0.4 \\
\hline Item 3 & 1.81 & 1.27 & 1.38 & 0.60 & $0.38^{* * *}$ & $0.67^{* * *}$ & 63 & 12.2 & 10.2 & 7.1 & 6.7 & 0.8 \\
\hline Item 4 & 2.87 & 1.41 & 0.07 & -1.36 & $0.19^{* * *}$ & $0.88^{* * *}$ & 22.8 & 22 & 14.6 & 24.4 & 15.4 & 0.8 \\
\hline Item 5 & 2.68 & 1.38 & 0.30 & -1.12 & $0.16^{* * *}$ & $0.89^{* * *}$ & 26.4 & 20.9 & 23.2 & 13.8 & 14.2 & 1.6 \\
\hline Item 6 & 3 & 1.48 & 0.01 & -1.41 & $0.17^{* * *}$ & $0.88^{* * *}$ & 22.4 & 19.3 & 17.3 & 18.1 & 22.8 & 0 \\
\hline Item 7 & 2.34 & 1.43 & 0.66 & -0.92 & $0.25^{* * *}$ & $0.82^{* * *}$ & 41.3 & 17.3 & 17.3 & 9.8 & 12.6 & 1.6 \\
\hline Item 8 & 2.77 & 1.49 & 0.20 & -1.34 & $0.19^{* * *}$ & $0.86^{* * *}$ & 29.5 & 15.4 & 21.3 & 13.8 & 18.9 & 1.2 \\
\hline Item 9 & 2.69 & 1.49 & 0.22 & -1.43 & $0.20^{* * *}$ & $0.85^{* * *}$ & 32.7 & 16.9 & 13.8 & 20.9 & 15.4 & 0.4 \\
\hline Item 10 & 2.04 & 1.26 & 1.11 & 0.23 & $0.26^{* * *}$ & $0.76^{* * *}$ & 44.9 & 26.4 & 13.4 & 5.5 & 8.3 & 1.6 \\
\hline Item 11 & 2.83 & 1.44 & 0.09 & -1.35 & $0.16^{* * *}$ & $0.88^{* * *}$ & 26.4 & 17.7 & 18.5 & 21.3 & 16.1 & 0 \\
\hline Item 12 & 2.24 & 1.44 & 0.75 & -0.91 & $0.29 * * *$ & $0.78^{* * *}$ & 46.5 & 16.5 & 11 & 13 & 11 & 2 \\
\hline Item 13 & 2.40 & 1.53 & 0.56 & -1.22 & $0.28^{* * *}$ & $0.79^{* * *}$ & 45.3 & 11 & 15 & 12.2 & 15 & 1.6 \\
\hline Item 14 & 3.06 & 1.64 & -0.06 & -1.63 & $0.20^{* * *}$ & $0.82^{* * *}$ & 29.9 & 11.4 & 11.4 & 17.3 & 19.9 & 0 \\
\hline Item 15 & 3.37 & 1.47 & -0.36 & -1.25 & $0.19^{* * *}$ & $0.86^{* * *}$ & 16.5 & 12.6 & 19.7 & 17.7 & 32.3 & 1.2 \\
\hline Item 16 & 3.31 & 1.46 & -0.29 & -1.26 & $0.19^{* * *}$ & $0.86^{* * *}$ & 17.3 & 12.2 & 22.8 & 16.1 & 30.7 & 0.8 \\
\hline Item 17 & 2.80 & 1.60 & -0.16 & -1.57 & $0.22^{* * *}$ & $0.82^{* * *}$ & 33.9 & 14.2 & 11.8 & 17.3 & 22.4 & 0.4 \\
\hline Item 18 & 2.48 & 1.48 & 0.51 & -1.17 & $0.22^{* * *}$ & $0.83^{* * *}$ & 37.8 & 18.5 & 15.4 & 12.6 & 15 & 0.8 \\
\hline Item 19 & 3.15 & 1.37 & -0.06 & -1.15 & $0.16^{* * *}$ & $0.88^{* * *}$ & 15 & 17.7 & 28.7 & 14.6 & 24 & 0 \\
\hline Item 20 & 2.82 & 1.54 & 0.20 & -1.45 & $0.18^{* * *}$ & $0.85^{* * *}$ & 29.1 & 18.1 & 16.9 & 12.2 & 23.2 & 0.4 \\
\hline \multicolumn{13}{|c|}{ Subsample $2(\mathrm{~N}=254)$} \\
\hline Item 1 & 2.58 & 1.28 & 0.38 & -1.01 & $0.22^{* * *}$ & $0.89^{* * *}$ & 23.6 & 30.7 & 16.9 & 19.3 & 8.7 & 0.8 \\
\hline Item 2 & 2.96 & 1.42 & -0.00 & -1.35 & $0.18^{* * *}$ & $0.89^{* * *}$ & 21.3 & 20.9 & 16.1 & 23.6 & 18.1 & 0 \\
\hline Item 3 & 1.78 & 1.13 & 1.25 & 0.50 & $0.36^{* * *}$ & $0.72^{* * *}$ & 60.6 & 12.6 & 16.5 & 6.3 & 3.1 & 0.8 \\
\hline Item 4 & 2.76 & 1.39 & 0.14 & -1.34 & $0.19^{* * *}$ & $0.88^{* * *}$ & 24.8 & 22.8 & 13.8 & 25.2 & 11.8 & 1.6 \\
\hline Item 5 & 2.51 & 1.33 & 0.44 & 0.15 & $0.20^{* * *}$ & $0.87^{* * *}$ & 29.9 & 23.6 & 20.5 & 14.6 & 10.2 & 1.2 \\
\hline Item 6 & 2.93 & 1.51 & 0.02 & -1.43 & $0.17^{* * *}$ & $0.86^{* * *}$ & 27.2 & 13.8 & 18.9 & 18.5 & 21.3 & 0.4 \\
\hline Item 7 & 2.36 & 1.39 & 0.49 & -1.17 & $0.25^{* * *}$ & $0.83^{* * *}$ & 41.3 & 14.6 & 16.9 & 17.7 & 8.3 & 1.2 \\
\hline Item 8 & 2.54 & 1.40 & 0.40 & -1.14 & $0.21^{* * *}$ & $0.85^{* * *}$ & 33.1 & 18.5 & 20.5 & 14.6 & 12.2 & 1.2 \\
\hline Item 9 & 2.74 & 1.44 & 0.25 & -1.24 & $0.17^{* * *}$ & $0.87^{* * *}$ & 28 & 18.1 & 23.2 & 13 & 17.7 & 0 \\
\hline Item 10 & 1.99 & 1.17 & 0.99 & -0.04 & $0.28^{* * *}$ & $0.79^{* * *}$ & 46.5 & 24 & 14.6 & 9.4 & 3.9 & 1.6 \\
\hline Item 11 & 2.79 & 1.50 & 0.13 & -1.46 & $0.20^{* * *}$ & $0.85^{* * *}$ & 19.9 & 16.5 & 14.2 & 21.3 & 17.3 & 0.8 \\
\hline Item 12 & 2.36 & 1.43 & 0.63 & -1.01 & $0.25^{* * *}$ & $0.81^{* * *}$ & 40.6 & 19.3 & 14.6 & 12.6 & 12.2 & 0.8 \\
\hline Item 13 & 2.57 & 1.50 & 0.36 & -1.33 & $0.24^{* * *}$ & $0.83^{* * *}$ & 37.8 & 12.6 & 18.5 & 14.2 & 15.7 & 1.2 \\
\hline Item 14 & 2.86 & 1.66 & 0.11 & -1.67 & $0.22^{* * *}$ & $0.81^{* * *}$ & 34.3 & 13.8 & 7.9 & 16.9 & 26 & 1.2 \\
\hline Item 15 & 3.57 & 1.38 & -0.48 & -1.06 & $0.23^{* * *}$ & $0.85^{* * *}$ & 10.2 & 14.2 & 20.9 & 16.9 & 37.4 & 0.4 \\
\hline Item 16 & 3.25 & 1.45 & -0.23 & -1.26 & $0.18^{* * *}$ & $0.87^{* * *}$ & 18.1 & 12.2 & 24 & 16.1 & 28.3 & 1.2 \\
\hline Item 17 & 2.76 & 1.58 & 0.21 & -1.54 & $0.22^{* * *}$ & $0.82^{* * *}$ & 33.9 & 16.1 & 11.4 & 17.3 & 21.3 & 0 \\
\hline Item 18 & 2.23 & 1.32 & 0.76 & -0.60 & $0.25^{* * *}$ & $0.82^{* * *}$ & 42.1 & 19.3 & 20.1 & 8.7 & 9.1 & 0.8 \\
\hline Item 19 & 2.84 & 1.39 & 0.15 & -1.18 & $0.15^{* * *}$ & $0.88^{* * *}$ & 23.2 & 18.5 & 26 & 14.6 & 17.3 & 0.4 \\
\hline Item 20 & 2.82 & 1.53 & 0.14 & -1.42 & $0.20^{* * *}$ & $0.85^{* * *}$ & 31.1 & 11.4 & 22 & 13.8 & 20.9 & 0.8 \\
\hline
\end{tabular}

${ }^{* * *} \mathrm{p}<0.001$. S: Skewness, K: Kurtosis, K-S: Kolmogorov-Smirnov test of normality, S-W: Shapiro-Wilk test of normality, Sd: strongly disagree, D: disagree, Pa: partially agree, A: agree, Sa: strongly agree 
tions for each item of a scale should exceed 0.30, recommended as the standard for supporting item-internal consistency. ${ }^{27}$

A confirmatory factor analysis, using ML Maximum Likelihood robust estimation procedures, was performed using the EQS Structural Equation Program Version 6.1. ${ }^{28}$ To statistically evaluate the closeness of the hypothetical model to the empirical data, multiple goodness-of-fit indexes were used, including the ratio of the chi-square to degrees of freedom $\left(\chi^{2}\right)$ df), the Non-Normed Fit Index (NNFI), the Comparative Fit Index (CFI), the Standardized Root Mean Square Residual (SRMR), and the Root Mean Square Error of Approximation (RMSEA). NNFI and CFI values of 0.95 or greater and SRMR and RMSEA values of 0.05 or less are interpreted as evidence of models that fit well. ${ }^{29}$

\section{RESULTS}

\section{Item analysis}

Table 1 gives item characteristics for both examined subsamples. Included are mean, standard deviation, skewness and kurtosis, Kolmogorov-Smirnov and Shapiro-Wilk tests of normality, and response frequency of all the 20 items.

The mean values of the TAS-20 items ranged from 1.81 to 3.37 for the first random subsample and from 1.78 to 3.57 for the second random subsample.

The distributional properties of each item were examined by inspecting the skewness and kurtosis and the pattern of response frequency. The univariate skewness values ranged from -0.36 to 1.38 for the first random subsample and from -0.48 to 1.25 for the second random subsample, and the univariate kurtosis values ranged from -1.63 to 0.60 for the first random subsample and from -1.54 to 0.50 for the second random subsample, thus suggesting that some items deviated from a normal distribution.

The statistical significance of both Kolmogorov-Smirnov and Shapiro-Wilk tests of normality revealed that each item had a distribution that was significantly different from normal and, as a result, suggested that estimation procedures that assume a normal distribution may not be appropriate for examining the underlying factor structure of the TAS-20. ${ }^{30,31}$ Based on these findings, the principal axis factoring method was chosen for exploratory factor analyses, and Maximum Likelihood robust estimation procedures were applied for confirmatory factor analyses.

\section{Exploratory factor analysis}

Data from the first random subsample of respondents were subjected to exploratory factor analysis to identify the likely factor structure of the questionnaire. With our 20-item scale, we were able to satisfy the minimum ten participants-per-item ratio that is usually recommended for factor analysis. ${ }^{32}$ A sample of 12.7 subjects per item ensured that reliable factors would emerge from the factor analysis.

Bartlett's Test of Sphericity (chi-square $=645.55$; $\mathrm{df}=190$ ) was significant $(\mathrm{p}<0.001)$, indicating that the correlation matrix is factorable based on a suitable level of variable interrelations, and the Kaiser-Meyer-Olkin Measure of Sampling Adequacy was 0.73 , demonstrating a sufficient proportion of common variance in our variables. ${ }^{33}$ Both results, thus, suggest that items were appropriate for proceeding with factor analysis.

Parallel analysis determined six factors to be extracted (Table 2, Figure 1). The resulting number of factors is evidently overdefined, with several factors comprised by only two indicators, some items with loadings less than 0.30 on all factors, and a number of items loading simultaneously on two factors, without a difference of at least 0.30 between loading on the primary factor and loading on other factors.

To determine the number of factors to extract, the scree plot and eigenvalues were also examined. The Kaiser-Guttman's criterion is known to potentially inflate the number of factors to be extracted, because it is sensitive to the number of variables in the analysis. Hence, Cattell's ${ }^{25}$ scree test is considered a more reliable indicator of the number of factors to be extracted because it draws on the relative values of the eigenvalues and so is not sensitive to the number of variables in the

Table 2. Raw data eigenvalues, mean and percentile random data eigenvalues

\begin{tabular}{cccc}
\hline Root & Raw data & Means & Percentiles \\
\hline 1 & 2.727512 & 0.671885 & 0.783375 \\
2 & 0.982912 & 0.561611 & 0.647827 \\
3 & 0.716857 & 0.476683 & 0.549938 \\
4 & 0.616550 & 0.401487 & 0.464613 \\
5 & 0.374556 & 0.336233 & 0.399309 \\
6 & 0.308982 & 0.277025 & 0.332743 \\
7 & 0.199935 & 0.222245 & 0.272740 \\
8 & 0.100857 & 0.170140 & 0.216881 \\
9 & 0.050998 & 0.120885 & 0.167377 \\
10 & 0.013597 & 0.074091 & 0.115870 \\
11 & -0.014888 & 0.029912 & 0.068343 \\
12 & -0.045036 & -0.014410 & 0.022531 \\
13 & -0.060360 & -0.057389 & -0.019827 \\
14 & -0.123033 & -0.098599 & -0.066483 \\
15 & -0.155923 & -0.138569 & -0.103940 \\
16 & -0.209584 & -0.179834 & -0.148070 \\
17 & -0.236193 & -0.220703 & -0.188705 \\
18 & -0.240722 & -0.261850 & -0.231443 \\
19 & -0.300653 & -0.306280 & -0.272783 \\
20 & -0.314840 & -0.357965 & -0.317669 \\
\hline & & &
\end{tabular}


analysis. ${ }^{34}$ Cattell ${ }^{25}$ recommended that the number of factors to be extracted is the number of eigenvalues that lie well above the scree slope and is a more reliable test for the number of

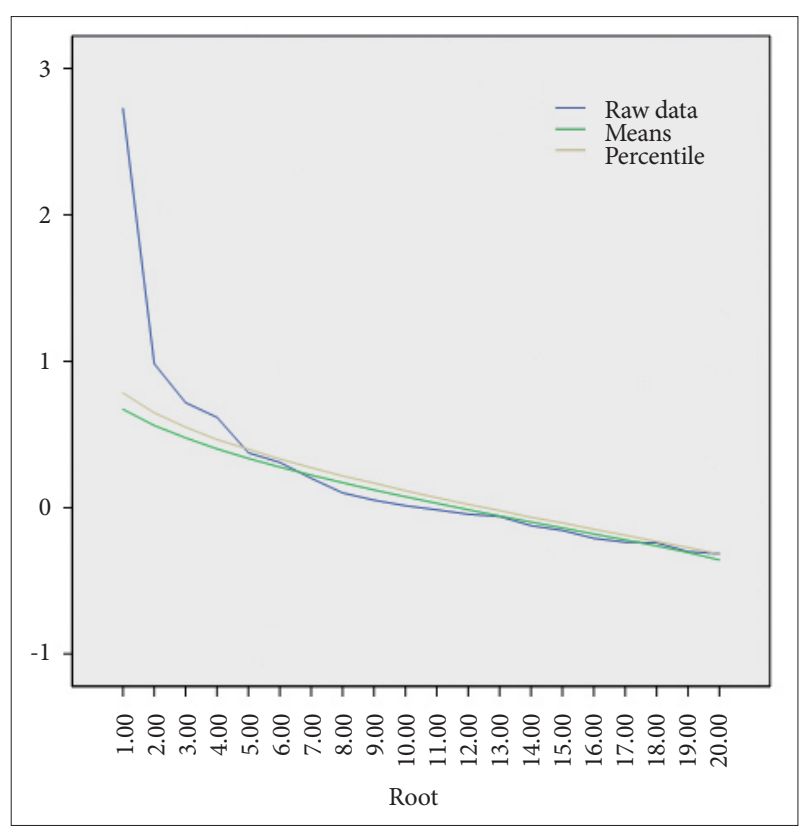

Figure 1. Raw data eigenvalues versus mean and percentile random data eigenvalues. factors in cases where there is a clear and easily interpretable scree slope. The eigenvalue greater than one criterion suggested extracting seven factors, accounting for $35.63 \%$ of the total variance. Inspection of the scree plot suggested a solution of up to four factors.

Based on the examination of the pattern of loadings and accepting a minimum of three items for each factor, we retained four factors explaining $27.54 \%$ of the total variance. Based on the resultant pattern matrix, item 20 "Looking for hidden meanings in movies or plays distracts from their enjoyment" that failed to load on any of the four factors was not retained (this item loaded: on F1 at -0.252 , on F2 at -0.131 , on F3 at $<0.10$, and on $\mathrm{F} 4$ at 0.168 ).

Factor 1, with an eigenvalue of 3.40 and responsible for

Table 4. Subscales intercorrelations

\begin{tabular}{ccccc}
\hline & F1 & F2 & F3 & F4 \\
\hline F1 & - & & & \\
F2 & $0.190^{* *}$ & - & & \\
F3 & $-0.217^{* *}$ & -0.020 & - & \\
F4 & $0.208^{* *}$ & $0.159^{*}$ & -0.020 & - \\
\hline
\end{tabular}

${ }^{*} \mathrm{p}<0.05,{ }^{* *} \mathrm{p}<0.01$. F1: difficulty identifying feelings, F2: difficulty describing feelings, F3: externally oriented thinking, F4: lack of subjective significance or importance of emotions

Table 3. Factor loadings of the TAS-20 items (pattern matrix)

\begin{tabular}{|c|c|c|c|c|}
\hline Item & F1 & F2 & F3 & $\mathrm{F} 4$ \\
\hline 7. I am often puzzled by sensations in my body & 0.700 & & & \\
\hline 13. I don't know what's going on inside me & 0.610 & & & \\
\hline 3. I have physical sensations that even doctors don't understand & 0.574 & & & \\
\hline 14. I often don't know why I am angry & 0.547 & & & \\
\hline 6. When I am upset I don't know if I am sad, frightened, or angry & 0.508 & & & \\
\hline 12. People tell me to describe my feelings more & 0.354 & & & \\
\hline 9. I have feelings that I can't quite identify & 0.321 & & & \\
\hline 4. I am able to describe my feelings easily (reverse keyed) & & 0.772 & & \\
\hline 2. It is difficult for me to find the right words for my feelings & & 0.608 & & \\
\hline 1. I am often confused about what emotion I am feeling & & 0.406 & & \\
\hline 5. I prefer to analyze problems rather than just describe them (reverse keyed) & & 0.321 & & \\
\hline 19. I find examination of my feelings useful in solving personal problems (reverse keyed) & & & 0.542 & \\
\hline 10. Being in touch with emotions is essential (reverse keyed) & & & 0.528 & \\
\hline 8. I prefer to just let things happen rather than to understand why they turned out that way & & & 0.357 & \\
\hline 18. I can feel close to someone, even in moments of silence (reverse keyed) & & & 0.355 & \\
\hline 17. It is difficult for me to reveal my innermost feelings, even to close friends & & & & 0.437 \\
\hline 15. I prefer talking to people about their daily activities rather than their feelings & & & & 0.422 \\
\hline 11. I find it hard to describe how I feel about people & & & & 0.367 \\
\hline 16. I prefer to watch "light" entertainment shows rather than psychological dramas & & & & 0.356 \\
\hline$\%$ explained variance & 14.50 & 5.64 & 3.85 & 3.55 \\
\hline
\end{tabular}

F1: difficulty identifying feelings, F2: difficulty describing feelings, F3: externally oriented thinking, F4: lack of subjective significance or importance of emotions 
Table 5. Fit indices for the orthogonal and oblique bi-factorial models

\begin{tabular}{lccccccccc}
\hline & $\chi^{2}$ & $\mathrm{df}$ & $\mathrm{p}$ & $\chi^{2} / \mathrm{df}$ & $\mathrm{NNFI}$ & $\mathrm{CFI}$ & SRMR & RMSEA & 90\% CI \\
\hline Orthogonal model & 106.81 & 33 & 0.000 & 3.24 & 0.75 & 0.82 & 0.16 & 0.10 & $0.076-0.117$ \\
Oblique model & 54.22 & 32 & 0.008 & 1.69 & 0.92 & 0.95 & 0.05 & 0.05 & $0.027-0.078$ \\
\hline
\end{tabular}

NNFI: Non-Normed Fit Index, CFI: Comparative Fit Index, SRMR: Standardized Root Mean Square Residual, RMSEA: Root Mean Square Error of Approximation

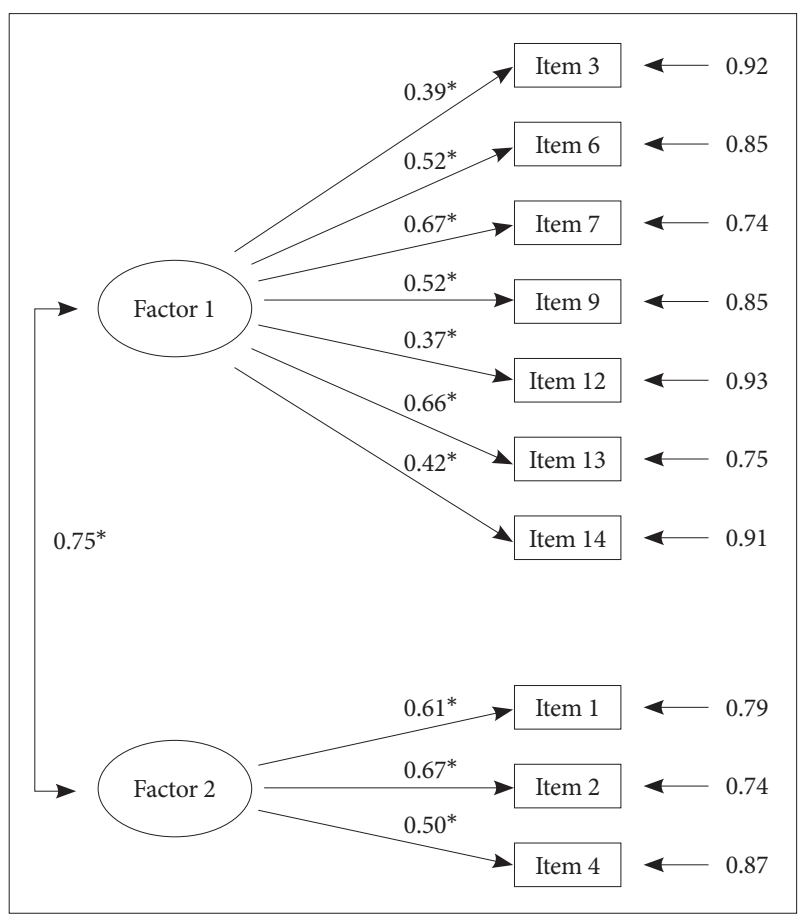

Figure 2. Empirical model (standardized solution). ${ }^{*} p<0.05$. Factor 1 : difficulty identifying feelings, Factor 2 : difficulty describing feelings.

$14.50 \%$ of the total variance for the questionnaire, included 7 items which loaded above 0.32 . The items with the highest loading are items 7 and 13 .

Factor 2, with 4 items loading above 0.32 , had an eigenvalue of 1.71 , and accounted for $5.64 \%$ of the total variance explained. The items with the highest loading are items 4 and 2.

Factor 3 , with 4 items loadings above 0.35 , had an eigenvalue of 1.52 and accounted for $3.85 \%$ of the total variance. The items 19 and 10 have the highest loading on this factor.

Factor 4 , with 4 items loading above 0.35 , had an eigenvalue of 1.41 , and accounted for $3.55 \%$ of the total variance. Items 17 and 15 have the highest loadings on this factor.

Items and factor loadings are presented in Table 3.

The revealed dimensions correlated significantly $(\mathrm{p}<0.01$, two-tailed tests) but moderately, with each other $(-0.22 \leq \mathrm{r} \leq$ $0.21, \mathrm{p}<0.01)$, except for the non-significant correlation between factor 2 (Difficulty describing feelings) and factor 3 (Externally oriented thinking) $(\mathrm{r}=-0.02)$ and between factor 3 (Externally oriented thinking) and factor 4 (Lack of subjective significance or importance of emotions) ( $\mathrm{r}=-0.02)$. The correlation between F2 and F4, although still significant ( $\mathrm{p}<0.05$, twotailed tests) was very weak $(\mathrm{r}=0.159)$ (Table 4$)$.

The first factor "Difficulty identifying feelings", consisting of seven variables, had a Cronbach's alpha of 0.69 , which delineates good internal consistency of this subscale. If one or more items of the first factor are eliminated, Cronbach's alpha drops off. The second factor "Difficulty describing feelings", involving four items and had a Cronbach's alpha of 0.52, which can be considered to be undesirable. One item was removed from this factor scale due to corrected item-total correlation below 0.30 (item 5 "I prefer to analyze problems rather than just describe them"). Thus, alpha for the second factor, now consisting of three variables, was 0.60. The third factor "Externally oriented thinking", consisting of four items, had a Cronbach's alpha of 0.40 . There were no items that would have increased the scale reliability if they were deleted. The fourth factor "Lack of subjective significance or importance of emotions", comprising four items, had a Cronbach's alpha of 0.40 . The deletion of any of the eight items could not increase the internal consistency of this dimension. These values are considered unacceptable and indicate poor internal homogeneity.

\section{Confirmatory factor analysis}

The confirmatory factor analysis performed on the second random subsample showed reasonable goodness-of-fit for the oblique bi-factorial model: [chi] ${ }^{2}(32, \mathrm{n}=254)=54.22 ; \mathrm{p}=0.008$; $\chi^{2} / \mathrm{df}=1.69 ; \mathrm{NNFI}=0.92 ; \mathrm{CFI}=0.95 ; \mathrm{SRMR}=0.05$; RMSEA $=$ $0.05 ; 90 \%$ confidence interval $=0.027-0.078$ (Table 5). All manifest variables loaded significantly $(\mathrm{p}<0.05)$ on their hypothesized latent factors. Figure 2 presents the standardized parameter estimates.

\section{DISCUSSION}

This study suggests that alexithymia is a construct which may be analysed also in younger adolescent populations. In accordance with several studies, ${ }^{8-11}$ we found that only two of the three factors of alexithymia (Difficulty identifying feelings, Difficulty describing feelings) had good psychometric properties. These two factors seem to represent the core of alexithymia in young adolescents. Instead the Externally oriented thinking subscale obtained a low internal consistency: these data 
are similar to findings published in different languages. ${ }^{1}$ We suppose that the Externally oriented thinking subscale is composed of items which are hard to understand for an adolescent (for instance, "I can feel close to someone, even in moments of silence", "I find examination of my feelings useful in solving personal problems", or "Looking for hidden meanings in movies or plays distracts from their enjoyment"). Yet, some items of this factor are strongly associated to the normal adult experience: e.g., it is improbable that adolescents look for a meaning in movies or cartoons.

Exploratory factor analysis highlighted a four-factor model: "Difficulty identifying feelings" (Items 3, 6, 7, 9, 12, 13, and 14), "Difficulty describing feelings" (Items 1, 2, 4, and 5), "Externally-oriented thinking" (Items 8, 10, 18, and 19), and "Lack of subjective significance or importance of emotions" (Items $11,15,16$, and 17). This solution presents some differences compared to traditional structure: for instance, the fourth factor is composed of items generally included in both the second factor (item 11 and item 17) and the third factor (item 15 and item 16). Besides, item 1 ("I am often confused about what emotion I am feeling") loaded on the second factor rather than on the first factor, and item 12 ("People tell me to describe my feelings more") loaded on the first factor rather than on the second factor.

Based on the performed confirmatory factor analysis, a twofactor structure model showed a good fit to the empirical data, as indicated by the fit indices. The oblique bi-factorial structure was comprised by "Difficulty identifying feelings" subscale (Items 3, 6, 7, 9, 12, 13, and 14), and "Difficulty describing feelings" subscale (Items 1, 2, and 4). Our outcomes confirm the nuclear role of the factor Difficulty identifying feelings and to lesser extent of the factor Difficulty describing feelings for young adolescents' emotional competences. Regarding the third factor, it would be composed of items linked with attitude and social experiences of adolescents.

Limitations of our study might be related to the use of a selfreport focused on reflection about oneself and one's cognitive, emotional, and behavioural abilities.

Based on the outcomes of our research we support the idea of evaluating adolescents for alexithymia. Nevertheless, we agree with Parker and colleagues ${ }^{10}$ that "applying adult scoring norms to adolescent respondents might lead to systematic overidentification of alexithymia in this population" (pp. 805-806). For this reason, a new version of TAS-20 for young adolescents that includes items adequate to their cognitive and emotional development, and to their own life experiences should be sought.

\section{REFERENCES}

1. Taylor GJ, Bagby RM. Psychoanalysis and empirical research: the exam- ple of alexithymia. J Am Psychoanal Assoc 2013;61:99-133.

2. Taylor GJ, Bagby RM, Parker JDA. Disorders of Affect Regulation: Alexithymia in Medical and Psychiatric Illness. Cambridge: Cambridge University Press; 1997.

3. Sifneos PE. The prevalence of 'alexithymic' characteristics in psychosomatic patients. Psychother Psychosom 1973;22:255-262.

4. Gori A, Giannini M, Palmieri G, Salvini R, Schuldberg D. Assessment of Alexithymia: psychometric properties of the Psychological Treatment Inventory Alexithymia Scale (PTI-AS). Psychology 2012;3:231-236.

5. Taylor GJ. Psychosomatic Medicine and Contemporary Psychoanalysis. Madison, CT: International Universities Press; 1987.

6. Lumely MA, Neely LC, Burger AJ. The assessment of alexithymia in medical settings: implications for understanding and treating health problems. J Pers Assess 2007;89:230-246.

7. Craparo G, Gori A, Petruccelli I, Cannella V, Simonelli C. Intimate partner violence: relationships between alexithymia, depression, attachment styles, and coping strategies of battered women. J Sex Med 2014;11: 1484-1494.

8. Rieffe C, Oosterveld P, Terwogt MM. An alexithymia questionnaire for children: factorial and concurrent validation results. Pers Indiv Differ 2006;40:123-133.

9. Zimmermann G, Quartier V, Bernard M, Salamin V, Maggiori C. The 20-item Toronto Alexithymia Scale: Structural validity, internal consistency and prevalence of alexithymia in a Swiss adolescent sample. Encephale 2007;33:941-946.

10. Parker JD, Eastabrook JM, Keefer KV, Wood LM. Can alexithymia be assessed in adolescents? Psychometric properties of the 20-Item Toronto Alexithymia Scale in younger, middle, and older adolescents. Psychol Assess 2006;22:798-808.

11. Oskis A, Clow A, Hucklebridge F, Bifulco A, Jacobs C, Loveday C. Understanding alexithymia in female adolescents: the role of attachment style. Pers Indiv Differ 2013;54:97-102.

12. Bagby RM, Parker JD, Taylor GJ. The twenty-item Toronto Alexithymia Scale--I. Item selection and cross-validation of the factor structure. J Psychosom Res 1994;38:23-32.

13. Bagby RM, Taylor GJ, Parker JD. The twenty-item Toronto Alexithymia Scale--II. Convergent, discriminant, and concurrent validity. J Psychosom Res 1994;38:33-40.

14. Sayar K, Kose S, Grabe HJ, Topbas M. Alexithymia and dissociative tendencies in an adolescent sample from Eastern Turkey. Psychiatry Clin Neurosci 2005;59:127-134.

15. Merino H, Godès A, Pombo MG. Alexithymia and psychological characteristics associated to eating attitudes in a sample of adolescents. Rev Psicopat Psic Clin 2002;7:35-44.

16. Ledouc KL. Alexithymia, trauma and posttraumatic stress disorder in incarcerated juvenile offenders. Dissertation Abstracts International: Section B; Sci Eng 2002;63(2B):1036.

17. Craparo G, Magnano P, Faraci P. Psychometric properties of the Italian version of the Self-Report Emotional Intelligence Test (SREIT). TPM 2014;21:121-133.

18. Paivio SC, McCulloch CR. Alexithymia as a mediator between childhood trauma and self-injurious. Child Abuse Negl 2004;28:339-354.

19. Bressi C, Taylor G, Parker J, Bressi S, Brambilla V, Aguglia E, et al. Crossvalidation of the factor structure of the 20-item Toronto Alexithymia Scale: an Italian multicenter study. J Psychosom Res 1996;41:551-559.

20. Caretti V, Porcelli P, Solano L, Schimmenti A, Bagby RM, Taylor GJ. Reliability and validity of the Toronto Structured Interview for Alexithymia in a mixed clinical and nonclinical sample from Italy. Psychiatry Res 2011;187:432-436.

21. Hair JF, Anderson RE, Tatham RL, Black WC. Multivariate Data Analysis, Fourth Edition. New Jersey: Prentice-Hall, Inc; 1995.

22. O' Connor B. SPSS and SAS programs for determining the number of components using parallel analysis and Velicer's MAP test. Behav Res Methods Instrum Comput 2000;32:396-402.

23. Horn JL. A rationale and test for the number of factors in factor analysis. 
Psychometrika 1965;30:179-185.

24. Kaiser HF. The application of electronic computers to factor analysis. Educ Psychol Meas 1960;20:141-151.

25. Cattell RB. The scree test for the number of factors. Multivariate Behav Res 1966;1:140-161.

26. Tabachnick BG, Fidell LS. Using Multivariate Statistics, Third Edition. New York: HarperCollins; 1996.

27. De Vellis R. Scale Development: Theory and Applications, Second Edition. Thousand Oaks: Sage; 2003.

28. Bentler PM. EQS 6 structural equations program manual. Multivariate Software, Encino, 2006
29. Hu L, Bentler PM. Cutoff criteria for fit indexes in covariance structure analysis: conventional criteria versus new alternatives. Struct Equ Modeling 1999;6:1-55.

30. Bollen KA. Structural Equations with Latent Variables. New York: Wiley; 1989.

31. Nunnally JC, Bernstein IH. Psychometric Theory. New York: McGrawHill; 1994.

32. Kaiser HF. An index of factorial simplicity. Psychometrika 1974;39:31-36.

33. Gorsuch RC. Factor Analysis. Hilsdale, NJ: Lawrence Erlhaum; 1983.

34. Zwick WR, Velicer WF. Comparison of five rules for determining the number of components to retain. Psychol Bull 1996;99:432-442. 